\title{
LEVANTAMENTO FITOSSOCIOLÓGICO EM UM FRAGMENTO DE FLORESTA ESTACIONAL SEMIDECÍDUA, NO MUNICÍPIO DE SÃO CARLOS, SP ${ }^{1}$
}

\author{
Luciana Álvares da Silva ${ }^{2}$ \\ João Juares Soares ${ }^{3}$
}

Recebido em 16/02/2001. Aceito em 10/12/2001.

\begin{abstract}
RESUMO - (Levantamento fitossociológico em um fragmento de floresta estacional semidecídua, no município de São Carlos, SP). O presente trabalho teve por objetivo a análise de parâmetros fitossociológicos em um fragmento de floresta estacional semidecídua, no município de São Carlos - SP, situado entre $21^{\circ} 55^{\prime}$ e $22^{\circ} 00^{\prime}$ Sul e $47^{\circ} 48^{\prime}$

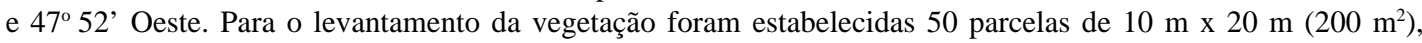
distribuídas perpendicularmente a uma trilha existente no interior do fragmento. Em cada parcela foram amostrados todos os indivíduos com diâmetro à altura do peito (DAP) igual ou maior a $5 \mathrm{~cm}$, onde foi medido o diâmetro, a altura, anotado o nome da espécie e coletado material para herborização. Foram encontrados 1343 indivíduos por hectare. As espécies que apresentaram maior valor de importância (VI) foram: Metrodorea nigra (33,09\%), Pachystroma longifolium (22,64\%), Aspidosperma ramiflorum (20,41\%), Actinostemon communis (17,38\%), Croton floribundus (12,70\%), Savia dictyocarpa (12,14\%), Ocotea pretiosa $(10,24 \%)$ e Machaerium stipitatum $(10,01 \%)$, que juntas somaram $46,20 \%$ do VI total e as 92 espécies restantes somaram 53,80\%.
\end{abstract}

Palavras-chave - Estrutura da comunidade, fragmento florestal, floresta semidecídua

\begin{abstract}
Phytosociological survey of arboreal vegetation of a mesophyllous semideciduous forest fragment, in municipality São Carlos, São Paulo State). The objective of was a to analise the phytosociological parameters of a semideciduous forest fragment in a secondary forest, São Carlos, São Paulo State ( $21^{\circ} 55^{\prime}$ 'S and $47^{\circ} 48^{\prime \prime} \mathrm{W}$ ). Fifty plots of $10 \mathrm{~m} \times 20 \mathrm{~m}\left(200 \mathrm{~m}^{2}\right)$ were established and distributed perpendiculary to a path in the forest fragment. Trees with a breast height of at least $5 \mathrm{~cm}$ of diameter (DBH) were tagged, measured, and identified. 1,343 individuals were sampled in the phytosociologic study. The species with the highest importance value (IV) were: Metrodorea nigra (33.09\%), Pachystroma longifolium (22.64\%), Aspidosperma ramiflorum (20.41\%), Actinostemon communis (17.38\%), Croton floribundus (12.70\%), Savia dictyocarpa (12.14\%), Ocotea pretiosa (10.24\%) and Machaerium stipitatum $(10.01 \%)$, that together comprised $46.20 \%$ of total IV and while the 92 remaining species comprised $53.80 \%$.
\end{abstract}

Key words - Community structure, forest fragment, semideciduous forest

\footnotetext{
1 Parte da tese de doutorado do primeiro autor

2 Doutora do PPG-ERN - UFSCar - e-mail: 1silva@ cenargen.embrapa.br

3 Departamento de Botânica - UFSCar e Prof. visitante da UEM. e-mail: juares@ power.ufscar.br Rodovia Washington Luiz, KM 235, São Carlos - SP - Cep: 13565-905 - C.P. 676.
} 


\section{Introdução}

No Brasil pode-se considerar a ocorrência dos seguintes biomas: a Floresta pluvial (Amazônica e Atlântica), a Floresta temperada quente, a Floresta estacional (Semidecidual e Decidual), o Cerrado, a Caatinga, os Campos e o Pantanal, sendo que a localização geográfica destes biomas, segundo Ribeiro e Walter (1993), é condicionada, predominantemente, por fatores climáticos e edáficos.

Nas regiões sul e sudeste, as florestas tropicais vêm sofrendo um aumento constante de intensidade, freqüência e tamanho das perturbações antrópicas, mas, muitas vezes, é possível recuperar a cobertura florestal através da regeneração natural (Viana 1987).

No Estado de São Paulo, os ecossistemas florestais que antes cobriam mais de $80 \%$ da superfície, desde o início de seu processo de desenvolvimento, foram reduzidos, drasticamente, a menos de 5\% da área do Estado (CONSEMA 1985).

A introdução da cultura cafeeira foi a principal bandeira de desenvolvimento do estado. Sendo exigente em clima e solo, com a sua expansão, ocorreu a ocupação de terras virgens e cobertas por matas (Victor 1975).

Os fragmentos florestais remanescentes são definidos como qualquer área de vegetação natural contínua, interrompidos por barreiras antrópicas ou naturais capazes de diminuir significativamente o fluxo de animais, pólen e/ou sementes (Viana 1990). Estes fragmentos apresentam sérios problemas, como um grande número de árvores mortas, alta ocorrência de cipós, um grande número de espécies raras e poucos indivíduos e espécies pertencentes a estádios mais avançados da sucessão (Almeida 1996, Viana 1990), porém, são fundamentais para a conservação da biodiversidade, devendo-se adotar técnicas apropriadas para a recuperação e o manejo.

Para um manejo sustentável efetivo existe a necessidade de desenvolvimento de sistemas de manejo adequados às florestas tropicais, sendo necessários conhecimentos de suas características biológicas e ecológicas, que possibilitem um bom manejo sob bases sustentáveis ambiental, econômica e social (Ferreira, 1997).

O presente trabalho teve por objetivo o levantamento da estrutura da comunidade arbórea em um fragmento de floresta estacional semidecídua da Fazenda Canchim, São Carlos, SP.

\section{Material e métodos}

O presente trabalho foi realizado na Reserva de Floresta Estacional Semidecídua, na Fazenda Canchim, de propriedade da Embrapa Pecuária Sudeste - CPPSE, localizada no município de São Carlos, São Paulo, entre 21 ${ }^{\circ} 55^{\prime}$ e $22^{\circ} 00^{\prime}$ Sul e $47^{\circ} 48^{\prime}$ e $47^{\circ} 52^{\prime}$ 'Oeste. O clima da região de São Carlos, segundo a classificação de Köppen, é do tipo de transição entre $\mathrm{Cwa}_{\mathrm{i}}$ $\mathrm{Aw}_{\mathrm{i}}$ (clima quente de inverno seco para tropical com verão úmido e inverno seco) (Tolentino, 1967). A precipitação média anual foi de 1440 $\mathrm{mm}$. A temperatura média das médias anual foi de $26,82^{\circ} \mathrm{C}$ e a média das mínimas $15,63^{\circ} \mathrm{C}$. A reserva apresenta topografia plana, levemente ondulada e altitude média de $850 \mathrm{~m}$. A unidade de solo predominante é a do Latossolo Vermelho Distrófico típico.

$\mathrm{O}$ fragmento apresenta uma área de aproximadamente 112 ha de floresta estacional semidecídua, segundo a classificação do IBGE (1993).

Para o levantamento fitossociológico foram utilizadas parcelas retangulares de área fixa de 0,02 ha $(10 \mathrm{~m} \times 20 \mathrm{~m})$. Foram demarcadas 50 parcelas, totalizando uma área de amostragem de 1 ha. A demarcação das parcelas foi feita seguindo uma orientação perpendicular à trilha principal que corta o fragmento. A distância entre as parcelas foi de $10 \mathrm{~m}$ e entre cada linha $50 \mathrm{~m}$. Em cada parcela foi feito o levantamento de todos os indivíduos arbóreo-arbustivos, vivos ou mortos em pé, com DAP igual ou superi- 
or a $5 \mathrm{~cm}$. Os indivíduos foram marcados com plaquetas e identificados pelo nome científico, e quando não identificados, foram coletados para posterior identificação. Os indivíduos que apresentaram estruturas férteis foram depositados no Herbário do Departamento de Botânica da UFSCar. Foi medido o diâmetro com fita métrica e a altura total foi estimada visualmente por comparação com uma vara de $10 \mathrm{~m}$ (Silva 2001).

Os parâmetros da estrutura horizontal foram calculados por meio das expressões descritas por Curtis \& McIntosh (1950), MuellerDombois \& Ellenberg (1974) e Lamprecht (1990).

\section{Resultados e discussão}

Foram amostradas 50 parcelas envolvendo 1343 indivíduos, sendo 1239 vivos e 104 mortos ainda em pé. As espécies amostradas no levantamento fitossociológico estão apresentadas na Tab. 1. A análise estrutural, representada pelos parâmetros fitossociológicos, é apresentada na Tab. 2, a qual mostra a relação das espécies em ordem decrescente de valor de importância (VI) e seus respectivos parâmetros fitossociológicos.

Excluindo as árvores mortas, 21 espécies contribuíram com aproximadamente $75 \%$ da soma total do VI, sendo que apenas oito espécies apresentaram VI igual ou maior a 10.

Um grande número de espécies (55\%) apresentou VI menor que 1\%, e, segundo Martins (1979), é uma característica das florestas tropicais a presença de um grande número de espécies com baixo VI. Poucas espécies detêm altos valores relativos de densidade, de freqüência e de dominância, enquanto muitas espécies, com poucos indivíduos, têm baixo VI.

Foram encontradas 104 árvores mortas, perfazendo um total de $7,74 \%$ dos indivíduos amostrados, o que parece ser normal em florestas brasileiras. Como apresentou elevada freqüência, ocorrendo em $84 \%$ das parcelas, indica que não está havendo uma perturbação localizada. Dentre o total de árvores amostradas, Cavassan (1982) encontrou 5,8\% de árvores mortas, Struffaldi-De-Vuono (1985) 11,5\%, Martins (1991) 7,4\% e Tabanez et al. (1997) 11,3\%. A morte das árvores pode estar relacionada a acidentes (ventos, tempestades, queda de grandes ramos), doenças, perturbações antrópicas, ou ocorrer naturalmente por velhice (Martins 1991).

Para Lopes (1998), as árvores mortas, ainda em pé, têm valor ecológico para a fauna silvestre, fornecendo abrigo, local de nidificação, fonte indireta de alimento, entre outros.

Em fragmentos recém-isolados, a morte de árvores deve-se, provavelmente, às mudanças microclimáticas que ocorrem por ocasião do isolamento e, em fragmentos isolados há muito tempo, um grande número de árvores mortas mostra que o aumento de mortalidade de árvores não ocorre só imediatamente após o isolamento, mas persiste por muito tempo (Tabanez et al. 1997).

Segundo resultados apresentados na Tab. 2, há 37 espécies com um indivíduo por hectare, $\mathrm{o}$ que representa $37 \%$ do número de espécies encontradas no fragmento. É um número muito elevado de espécies que ocorrem com apenas um indivíduo amostrado, indicando uma alta susceptibilidade à extinção local da espécie no fragmento, caso ocorra morte ou corte desses indivíduos. Pode ser devido à grande diversidade da flora, ao padrão de distribuição da espécie e a baixa densidade das populações, sendo que este número pode ser ainda maior, pois, segundo Tabanez et al. (1997), à medida que, provavelmente, todas as espécies mais comuns foram coletadas, muitas espécies raras podem ter passado despercebidas por problemas de amostragem.As dez espécies mais importantes com relação ao VI foram: Metrodorea nigra (33,09\%), Pachystroma longifolium (22,64\%), Aspidosperma ramiflorum (20,41\%), Actinostemon communis $(17,38 \%)$, Croton floribundus $(12,70 \%)$, Savia dictyocarpa $(12,14 \%)$, 
Tabela 1 . Lista das famílias e espécies ocorrentes no levantamento florístico da Reserva de Floresta Estacional Semidecídua (Fazenda Canchim), Embrapa - CPPSE, São Carlos - SP.

\section{FAMÍLIA/ESPÉCIE}

ANACARDIACEAE

Astronium graveolens Jacq.

ANNONACEAE

Annona cacans Warm.

Duguetia lanceolata St. Hil.

Rollinia syilvatica (A.St. Hil.) Mart.

Xylopia brasiliensis Spreng.

Xylopia sp.

\section{APOCYNACEAE}

Aspidosperma parvifolium A.DC.

Aspidosperma polyneuron Mull. Arg.

Aspidosperma ramiflorum Mull. Arg.

\section{ASTERACEAE}

Vernonia diffusa Less.

\section{BIGNONIACEAE}

Jacaranda micrantha Cham.

Zeyheria tuberculosa (Vell.) Bur.

\section{BOMBACACEAE}

Ceiba speciosa St. Hil.

\section{BORAGINACEAE}

Cordia sericicalyx A .DC.

\section{CAESALPINIACEAE}

Holocalyx glaziovii Taub.

\section{CARICACEAE}

Jacaratia spinosa (Aubl.) A. DC.

\section{CECROPIACEAE}

Cecropia pachystachya Trecul

CELASTRACEAE

Maytenus ilicifolia Mart.

\section{NOME POPULAR REGIONAL}

Guaritá, gonçalo-alves

Cortição, araticum-cagão

Araticum, pindaíba

Araticum do mato, cortiça

Pau-de-mastro, pindaíba

Peroba-rosa

Guatambú, guatambú-amarelo

Pau-toucinho

Caroba, Carobão

Bolsa-de-pastor, ipê-tabaco

Paineira

Puleiro-de-morcego

Alecrim-de-campinas

Jacaratiá, mamãozinho

Embaúba

Espinheira-santa 
Tabela 1. (continuação).

FAMÍLIA/ESPÉCIE

Maytenus robusta Reissek

\section{COMBRETACEAE}

Terminalia brasiliensis (Cambess.) Eichler

\section{EUPHORBIACEAE}

Actinostemon communis (Mull. Arg.) Pax

Actinostemon concolor (Spreng.) Mull. Arg.

Alchornea glandulosa Poepp. \& Endl.

Croton floribundus Spreng.

Maprounea guianensis Aubl.

Micrandra elata Mull. Arg.

Pachystroma longifolium (Nees) I. M. Johnst.

Sapium glandulatum (Vell.) Pax

Savia dictyocarpa Mull. Arg.

\section{FABACEAE}

Centrolobium tomentosum Guill. Ex Benth.

Cyclolobium vecchi A.Samp. Ex Hoelne

Lonchocarpus guilleminianus (Tul.) Malme

Lonchocarpus sp.

Machaerium aculeatum Raddi

Machaerium nyctitans (Vell.) Benth

Machaerium stipitatum (DC.) Vogel

Myroxylon peruiferum L.f.

\section{FLACOURTIACEAE}

Casearia gossypiosperma Briquet

Casearia sylvestris $\mathrm{Sw}$.

\section{LAURACEAE}

Endlicheria paniculata (Spreng.) Macbride

Nectandra sp.

Ocotea martiana Mez.

\section{NOME POPULAR REGIONAL}

\author{
Cafezinho-do-mato
}

Capitão-do-mato, amarelinho

Laranjeira-brava

Pau-rainha

- Maria-mole

Capixingui

Bonifácio

Leiteiro

Canxim

Pau-de-leite

Guaraiuva

Araribá

Louveira

Rabo-de-macaco, embira-de-sapo

Jacarandá-de-espinho

Bico-de-pato, jacarandá-espinho

Pau-de-malho, feijão-cru

Bálsamo, óleo-de-cabreúva

Cambroé, pau-de-espeto

Guaçatonga, café-do-diabo

Canela-do-brejo 
Tabela 1. (continuação).

\section{FAMÍLIA/ESPÉCIE}

Ocotea pretiosa (Nees) Mez.

Ocotea sp.

\section{LECYTHIDACEAE}

Cariniana estrellensis Kuntze

\section{LOGANIACEAE}

Strychnos brasiliensis (Spreng) Mart.

\section{MALPIGHIACEAE}

Byrsonima sp.

\section{MYRSINACEAE}

Cybianthus densiflorus Miq.

\section{MYRTACEAE}

Eugenia cf blastantha (O.Berg) D. Legrand

Eugenia umbelliflora O. Berg.

Eugenia sp1.

Eugenia sp2.

Myrciaria tenella (DC.) O. Berg

NYCTAGINACEAE

Guapira opposita (Vell.) Reitz.

\section{PIPERACEAE}

Piper amalago L.

\section{PROTEACEAE}

Roupala brasiliensis Klotz.

\section{RHAMNACEAE}

Colubrina glandulosa Perkins

Rhamnidium elaeocarpum Reissek

RUBIACEAE

Chomelia obtusa Cham \& Schltdl.

Ixora warmingii Mull. Arg.

Ixora venulosa Benth.

\section{RUTACEAE}

\section{NOME POPULAR REGIONAL}

\author{
Canela-sassafraz
}

Jequitibá-branco

Salta-martinho

Grumixama-miúda

Guamirim

Cambuí

Maria-mole

Falso-jaborandi

Carne-de-vaca

Saraguagi-vermelho

Saraguagi-amarelo

Araribe 
Tabela 1. (continuação).

\section{FAMÍLIA/ESPÉCIE}

Galipea jasminiflora (A.St.Hil.) Engl.

Metrodorea nigra St. Hil.

Pilocarpus sp.

Zanthoxylum riedelianum Engl.

\section{SAPINDACEAE}

Allophyllus edulis Radlk. ex Warm.

Allophyllus guaraniticus Barkley \& Villa

Cupania vernalis Cambess

Diatenopteryx sorbifolia Radlk.

Matayba eleagnoides Radlk.

\section{SAPOTACEAE}

Chrysophyllum gonocarpum Engl.

SOLANACEAE

Solanum prealtum Sendtn.

\section{ULMACAE}

Celtis iguanea (Jacq.) Sargent

Trema micrantha (L.) Blume

\section{URTICACEAE}

Urera baccifera (L.) Gaud.

\section{NÃO IDENTIFICADAS}

Indeterminada 1

Indeterminada 2

Indeterminada 3

Indeterminada 4

Indeterminada 5

Indeterminada 6

Indeterminada 7

Indeterminada 8

Indeterminada 9

\section{NOME POPULAR REGIONAL}

\section{Gramixinga}

Chupa-ferro, carrapateira

Mamica-de-porca

Fruta-de-pombo

Baga-de-morcego

Camboatá, pau-de-cantil

Maria preta

Caqui-do-mato

Guatambú-de-leite

Crindiúva

Urtigão-vermelho 
Tabela 2. Parâmetros fitossociológicos da Reserva de Floresta Estacional Semidecídua, da Fazenda Canchim, São Carlos - SP, em ordem decrescente de VI = valor de importância; NA = número de amostras de ocorrência da espécie; $\mathrm{FA}=$ freqüência absoluta; $\mathrm{FR}=$ freqüência relativa; $\mathrm{DA}=$ densidade absoluta; $\mathrm{DR}=$ densidade relativa; DoA = dominância absoluta; $\mathrm{DoR}=$ dominância relativa; $\mathrm{VC}=$ valor de cobertura

\begin{tabular}{|c|c|c|c|c|c|c|c|c|c|}
\hline ESPÉCIE & NA & FA & FR & DA & DR & DoA & DoR & VI & VC \\
\hline Metrodorea nigra & 45 & 90,00 & 7,18 & 249,00 & 20,10 & 1,48 & 5,82 & 33,09 & 25,91 \\
\hline Pachystroma longifolium & 25 & 50,00 & 3,99 & 45,00 & 3,63 & 3,83 & 15,02 & 22,64 & 18,65 \\
\hline Aspidosperma ramiflorum & 38 & 76,00 & 6,06 & 100,00 & 8,07 & 1,60 & 6,28 & 20,41 & 14,35 \\
\hline Actinostemon communis & 38 & 76,00 & 6,06 & 117,00 & 9,44 & 0,48 & 1,88 & 17,38 & 11,32 \\
\hline Croton floribundus & 21 & 42,00 & 3,35 & 34,00 & 2,74 & 1,68 & 6,60 & 12,70 & 9,35 \\
\hline Savia dictyocarpa & 22 & 44,00 & 3,51 & 61,00 & 4,92 & 0,95 & 3,71 & 12,14 & 8,63 \\
\hline Ocotea pretiosa & 25 & 50,00 & 3,99 & 37,00 & 2,99 & 0,83 & 3,26 & 10,24 & 6,25 \\
\hline Machaerium stiptatum & 18 & 36,00 & 2,87 & 24,00 & 1,94 & 1,33 & 5,20 & 10,01 & 7,14 \\
\hline Inga marginata & 24 & 48,00 & 3,83 & 41,00 & 3,31 & 0,49 & 1,92 & 9,05 & 5,23 \\
\hline Holocalyx glaziovii & 10 & 20,00 & 1,59 & 12,00 & 0,97 & 1,47 & 5,75 & 8,32 & 6,72 \\
\hline Actinostemon concolor & 24 & 48,00 & 3,83 & 43,00 & 3,47 & 0,14 & 0,56 & 7,86 & 4,03 \\
\hline Centrolobium tomentosum & 13 & 26,00 & 2,07 & 20,00 & 1,61 & 1,06 & 4,16 & 7,85 & 5,78 \\
\hline Piptadenia gonoacantha & 9 & 18,00 & 1,44 & 17,00 & 1,37 & 1,19 & 4,66 & 7,47 & 6,03 \\
\hline Aspidosperma polyneuron & 16 & 32,00 & 2,55 & 22,00 & 1,78 & 0,71 & 2,77 & 7,10 & 4,54 \\
\hline Vernonia diffusa & 13 & 26,00 & 2,07 & 18,00 & 1,45 & 0,83 & 3,25 & 6,78 & 4,71 \\
\hline Pilocarpus sp. & 21 & 42,00 & 3,35 & 34,00 & 2,74 & 0,09 & 0,36 & 6,45 & 3,10 \\
\hline Jacaratia spinosa & 10 & 20,00 & 1,59 & 21,00 & 1,69 & 0,71 & 2,80 & 6,09 & 4,49 \\
\hline Alchornea glandulosa & 10 & 20,00 & 1,59 & 13,00 & 1,05 & 0,74 & 2,91 & 5,55 & 3,96 \\
\hline Inga striata & 11 & 22,00 & 1,75 & 23,00 & 1,86 & 0,33 & 1,31 & 4,92 & 3,17 \\
\hline Zanthoxylum riedelianum & 13 & 26,00 & 2,07 & 15,00 & 1,21 & 0,31 & 1,23 & 4,51 & 2,44 \\
\hline Guapira opposita & 14 & 28,00 & 2,23 & 18,00 & 1,45 & 0,17 & 0,68 & 4,36 & 2,13 \\
\hline Ficus guaranitica & 4 & 8,00 & 0,64 & 4,00 & 0,32 & 0,85 & 3,33 & 4,29 & 3,65 \\
\hline Rhamnidium elaeocarpus & 10 & 20,00 & 1,59 & 14,00 & 1,13 & 0,28 & 1,09 & 3,81 & 2,22 \\
\hline Astronium graveolens & 12 & 24,00 & 1,91 & 18,00 & 1,45 & 0,10 & 0,40 & 3,76 & 1,85 \\
\hline Galipea jasminiflora & 9 & 18,00 & 1,44 & 20,00 & 1,61 & 0,15 & 0,60 & 3,65 & 2,22 \\
\hline Trichilia catigua & 10 & 20,00 & 1,59 & 12,00 & 0,97 & 0,09 & 0,35 & 2,91 & 1,32 \\
\hline Cabralea canjerana & 6 & 12,00 & 0,96 & 7,00 & 0,56 & 0,29 & 1,15 & 2,67 & 1,71 \\
\hline Chrysophyllum gonocarpum & 8 & 16,00 & 1,28 & 12,00 & 0,97 & 0,08 & 0,30 & 2,55 & 1,27 \\
\hline Maprounea guianensis & 8 & 16,00 & 1,28 & 9,00 & 0,73 & 0,05 & 0,20 & 2,20 & 0,92 \\
\hline Urera baccifera & 5 & 10,00 & 0,80 & 9,00 & 0,73 & 0,16 & 0,62 & 2,14 & 1,35 \\
\hline Cecropia pachystachya & 5 & 10,00 & 0,80 & 6,00 & 0,48 & 0,21 & 0,81 & 2,09 & 1,30 \\
\hline
\end{tabular}


Tabela 2. (continuação).

\begin{tabular}{|c|c|c|c|c|c|c|c|c|c|}
\hline ESPÉCIE & NA & FA & FR & DA & DR & DoA & DoR & VI & VC \\
\hline Strychnos brasiliensis & 3 & 6,00 & 0,48 & 3,00 & 0,24 & 0,34 & 1,34 & 2,06 & 1,58 \\
\hline Cybianthus densiflorus & 6 & 12,00 & 0,96 & 7,00 & 0,56 & 0,13 & 0,53 & 2,05 & 1,09 \\
\hline Eugenia sp.1 & 7 & 14,00 & 1,12 & 9,00 & 0,73 & 0,04 & 0,18 & 2,02 & 0,90 \\
\hline Myroxylon peruiferum & 4 & 8,00 & 0,64 & 4,00 & 0,32 & 0,21 & 0,81 & 1,77 & 1,13 \\
\hline Indeterminada 1 & 1 & 2,00 & 0,16 & 1,00 & 0,08 & 0,30 & 1,19 & 1,43 & 1,27 \\
\hline Eugenia umbelliflora & 4 & 8,00 & 0,64 & 7,00 & 0,56 & 0,05 & 0,19 & 1,39 & 0,75 \\
\hline Trichilia hirta & 4 & 8,00 & 0,64 & 5,00 & 0,40 & 0,07 & 0,28 & 1,32 & 0,68 \\
\hline Myrciaria tenella & 5 & 10,00 & 0,80 & 5,00 & 0,40 & 0,03 & 0,11 & 1,31 & 0,51 \\
\hline Ocotea martiana & 2 & 4,00 & 0,32 & 5,00 & 0,40 & 0,13 & 0,51 & 1,23 & 0,91 \\
\hline Roupala brasiliensis & 4 & 8,00 & 0,64 & 5,00 & 0,40 & 0,04 & 0,17 & 1,21 & 0,57 \\
\hline Chorisia speciosa & 4 & 8,00 & 0,64 & 4,00 & 0,32 & 0,05 & 0,19 & 1,15 & 0,51 \\
\hline Jacaranda micrantha & 3 & 6,00 & 0,48 & 3,00 & 0,24 & 0,10 & 0,38 & 1,11 & 0,63 \\
\hline Solanum prealtum & 3 & 6,00 & 0,48 & 6,00 & 0,48 & 0,02 & 0,08 & 1,04 & 0,56 \\
\hline Sapium glandulatum & 2 & 4,00 & 0,32 & 6,00 & 0,48 & 0,05 & 0,21 & 1,01 & 0,69 \\
\hline Duguetia lanceolata & 3 & 6,00 & 0,48 & 4,00 & 0,32 & 0,03 & 0,11 & 0,91 & 0,43 \\
\hline Colubrina glandulosa & 3 & 6,00 & 0,48 & 3,00 & 0,24 & 0,05 & 0,19 & 0,91 & 0,43 \\
\hline Terminalia brasiliensis & 3 & 6,00 & 0,48 & 4,00 & 0,32 & 0,03 & 0,11 & 0,91 & 0,43 \\
\hline Guarea kunthiana & 3 & 6,00 & 0,48 & 3,00 & 0,24 & 0,05 & 0,18 & 0,90 & 0,42 \\
\hline Diatenopteryx sorbifolia & 3 & 6,00 & 0,48 & 3,00 & 0,24 & 0,04 & 0,17 & 0,89 & 0,41 \\
\hline Eugenia sp.2 & 3 & 6,00 & 0,48 & 4,00 & 0,32 & 0,02 & 0,07 & 0,88 & 0,40 \\
\hline Cedrela fissilis & 3 & 6,00 & 0,48 & 3,00 & 0,24 & 0,04 & 0,14 & 0,86 & 0,39 \\
\hline Casearia sylvestris & 2 & 4,00 & 0,32 & 3,00 & 0,24 & 0,06 & 0,23 & 0,79 & 0,47 \\
\hline Trichilia elegans & 3 & 6,00 & 0,48 & 3,00 & 0,24 & 0,01 & 0,04 & 0,76 & 0,28 \\
\hline Micrandra elata & 1 & 2,00 & 0,16 & 1,00 & 0,08 & 0,12 & 0,48 & 0,72 & 0,56 \\
\hline Lonchocarpus guilleminianus & 2 & 4,00 & 0,32 & 3,00 & 0,24 & 0,03 & 0,11 & 0,67 & 0,35 \\
\hline Annona cacans & 1 & 2,00 & 0,16 & 5,00 & 0,40 & 0,03 & 0,10 & 0,67 & 0,51 \\
\hline Cupania vernalis & 2 & 4,00 & 0,32 & 3,00 & 0,24 & 0,02 & 0,06 & 0,62 & 0,30 \\
\hline Xylopia sp. & 1 & 2,00 & 0,16 & 4,00 & 0,32 & 0,03 & 0,13 & 0,61 & 0,45 \\
\hline Lonchocarpus sp. & 1 & 2,00 & 0,16 & 1,00 & 0,08 & 0,09 & 0,35 & 0,59 & 0,43 \\
\hline Endlicheria paniculata & 2 & 4,00 & 0,32 & 2,00 & 0,16 & 0,02 & 0,07 & 0,55 & 0,23 \\
\hline Ficus enormis & 2 & 4,00 & 0,32 & 2,00 & 0,16 & 0,01 & 0,06 & 0,54 & 0,22 \\
\hline Machaerium nyctitans & 2 & 4,00 & 0,32 & 2,00 & 0,16 & 0,01 & 0,03 & 0,51 & 0,19 \\
\hline Piper amalago & 2 & 4,00 & 0,32 & 2,00 & 0,16 & 0,00 & 0,02 & 0,50 & 0,18 \\
\hline Ocotea sp. & 1 & 2,00 & 0,16 & 1,00 & 0,08 & 0,06 & 0,24 & 0,48 & 0,32 \\
\hline
\end{tabular}


Tabela 2. (continuação).

\begin{tabular}{lccccccccc}
\hline ESPÉCIE & NA & FA & FR & DA & DR & DoA & DoR & VI & VC \\
\hline Cariniana estrellensis & 1 & 2,00 & 0,16 & 3,00 & 0,24 & 0,02 & 0,07 & 0,47 & 0,31 \\
Indeterminada 2 & 1 & 2,00 & 0,16 & 1,00 & 0,08 & 0,05 & 0,20 & 0,44 & 0,28 \\
Xylopia brasiliensis & 1 & 2,00 & 0,16 & 1,00 & 0,08 & 0,05 & 0,19 & 0,43 & 0,27 \\
Indeterminada 3 & 1 & 2,00 & 0,16 & 1,00 & 0,08 & 0,04 & 0,16 & 0,40 & 0,25 \\
Cyclolobium vecchi & 1 & 2,00 & 0,16 & 1,00 & 0,08 & 0,04 & 0,15 & 0,39 & 0,23 \\
Anadenanthera macrocarpa & 1 & 2,00 & 0,16 & 1,00 & 0,08 & 0,04 & 0,15 & 0,39 & 0,23 \\
Trema micrantha & 1 & 2,00 & 0,16 & 2,00 & 0,16 & 0,01 & 0,02 & 0,34 & 0,18 \\
Rollinia silvatica & 1 & 2,00 & 0,16 & 1,00 & 0,08 & 0,02 & 0,10 & 0,34 & 0,18 \\
Casearia gossypiosperma & 1 & 2,00 & 0,16 & 1,00 & 0,08 & 0,02 & 0,08 & 0,32 & 0,16 \\
Indeterminada 4 & 1 & 2,00 & 0,16 & 1,00 & 0,08 & 0,02 & 0,08 & 0,32 & 0,16 \\
Indeterminada 5 & 1 & 2,00 & 0,16 & 1,00 & 0,08 & 0,02 & 0,08 & 0,32 & 0,16 \\
Anadenanthera colubrina & 1 & 2,00 & 0,16 & 1,00 & 0,08 & 0,02 & 0,08 & 0,32 & 0,16 \\
\hline
\end{tabular}

Ocotea pretiosa (10,24\%) e Machaerium stipitatum $(10,01 \%)$, que juntas somaram $46,20 \%$ do VI total e as 92 espécies restantes somaram $53,80 \%$.

A espécie Metrodorea nigra apresentou maior VI $(33,09 \%)$ em decorrência da grande abundância de sua população, com elevados valores de frequiência e densidade (Fig. 1). Já a espécie $\boldsymbol{P a}$ chystroma longifolium $(22,64 \%)$ apresentou o segundo maior VI, devido principalmente pela dominância.

Para o VC a posição das espécies não alterou muito, a não ser para a espécie Holocalyx glaziovii, por apresentar maior valor de dominância que Ocotea pretiosa, ocupando a sua posição (Fig. 2).

A maioria dos fragmentos, encontram-se, atualmente, bastante degradada, com uma alta porcentagem de árvores mortas, alta ocorrência de lianas e algumas populações específicas instáveis, o que pode comprometer o futuro desses fragmentos. O estudo do manejo adequado do fragmento, de proteção contra incêndios, de análise da influência das lianas na queda de árvores e regeneração de clareiras e das populações de espécies instáveis, principalmente de secundárias tardias, de- veria receber atenção especial para a recuperação e manutenção deste fragmento florestal.

Os resultados aqui apresentados fornecem subsídios para estratégias de recuperação e manejo de fragmentos de florestas estacionais semideciduais.

\section{Agradecimentos}

A Embrapa Pecuária Sudeste - CPPSE, pela permissão para a realização deste trabalho na Reserva de Floresta Estacional Semidecídua. Ao Dr. Odo Primavesi (CPPSE), pelas facilidades para realização do trabalho e informações obtidas. Ao Conselho Nacional de Desenvolvimento Científico e Tecnológico - CNPq, pelo financiamento do projeto.

\section{Referências bibliográficas}

Almeida, D.S. 1996. Florística e estrutura de um fragmento de floresta atlântica, no município de Juiz de Fora, Minas Gerais. Dissertação de Mestrado. Universidade Federal de Viçosa, Viçosa. 


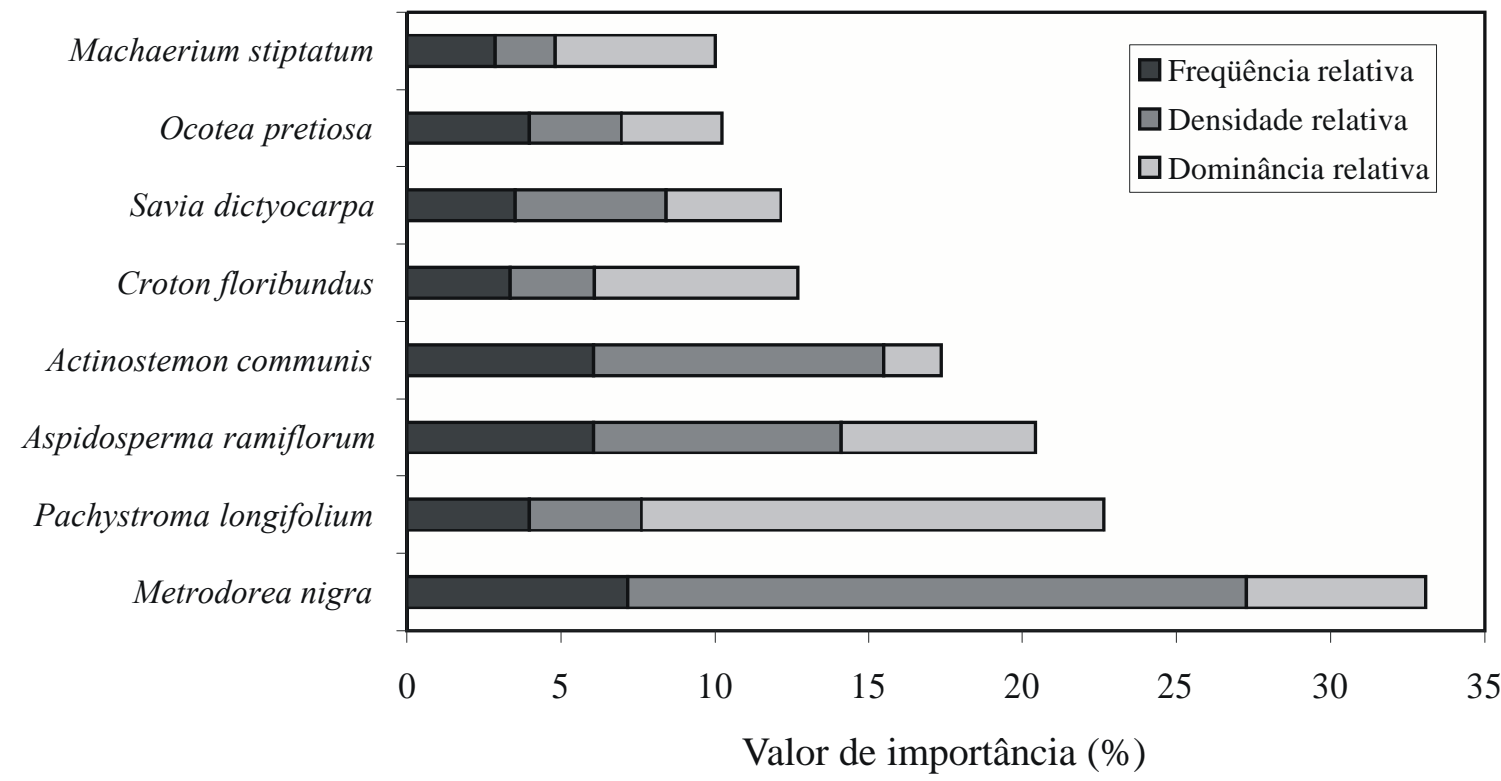

Figura 1. Valor de importância das principais espécies amostradas no levantamento fitossociológico da Reserva de Floresta Estacional Semidecídua, da Fazenda Canchim, São Carlos - SP.

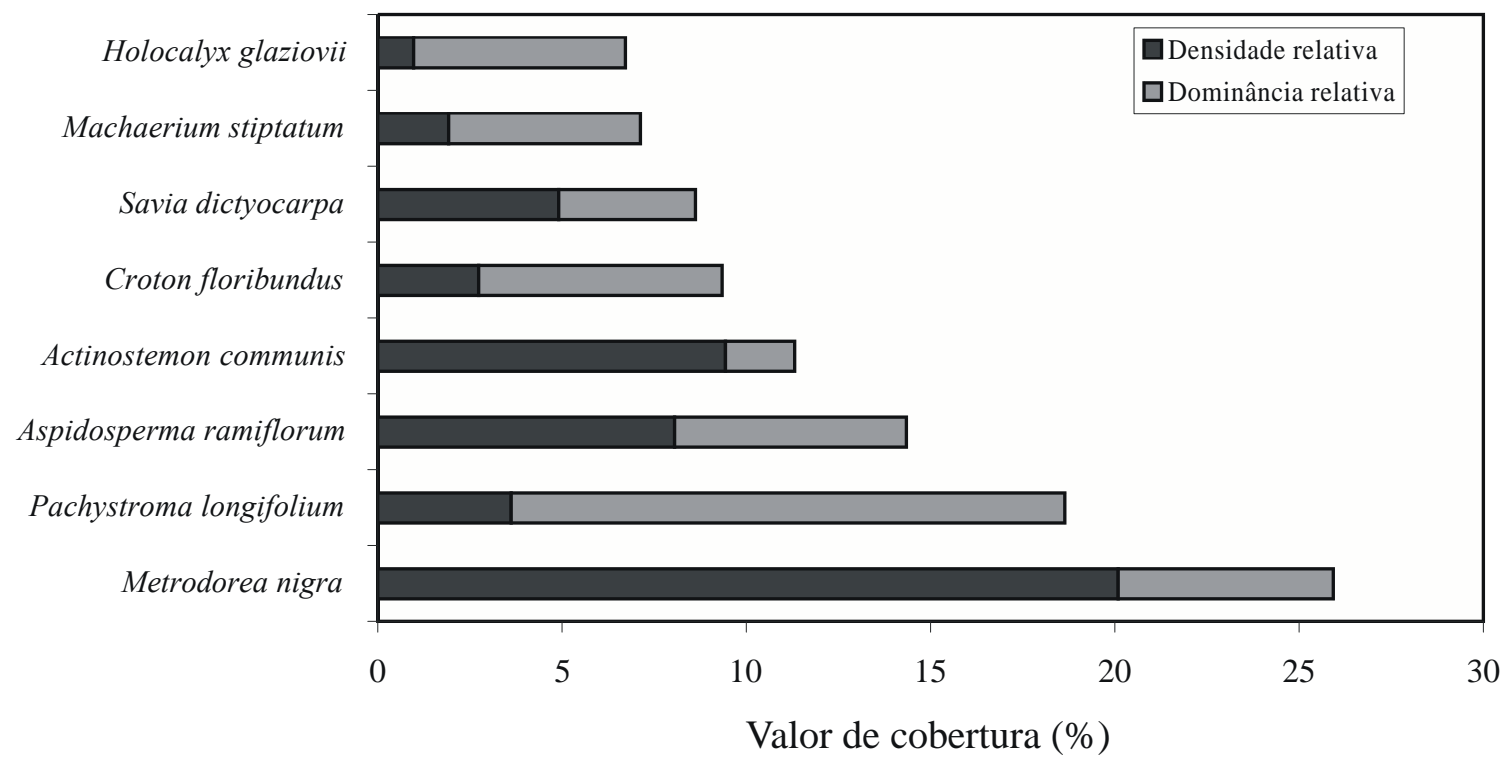

Figura 2. Valor de cobertura das principais espécies amostradas no levantamento fitossociológico da Reserva de Floresta Estacional Semidecídua, da Fazenda Canchim, São Carlos - SP. 
Cavassan, O. 1982. Levantamento fitossociológico da vegetação arbórea da mata da Reserva Estadual de Bauru, utilizando o método dos quadrantes. Dissertação de Mestrado. Universidade Estadual de São Paulo, Rio Claro.

CONSEMA. Conselho Estadual do Meio Ambiente. 1985. Áreas naturais do Estado de São Paulo.

Curtis, J.T. \& McInstosh, R.P. R.P. 1950. The interrelation of certain analytic and synthetic phytosociologiacal characters. Ecology 31:434-445.

Ferreira, R.L.C. 1997. Estrutura e dinâmica de uma floresta secundária de transição, Rio Vermelho e Serra Azul de Minas, MG. Tese de Doutorado. Universidade Federal de Viçosa, Viçosa.

Ibge - Instituto Brasileiro de Geografia e Estatística. 1993. Classificação da vegetação brasileira, adaptada a um sistema universal. IBGE, Rio de Janeiro.

Lamprecht, H. 1990. Silvicultura nos trópicos: ecossistemas florestais e respectivas espécies arbóreas - possibilidades e métodos de aproveitamento sustentado. GTZ. 343p.

Lopes, W.P. 1998. Florística e fitossociologia de um trecho de vegetação arbórea no Parque Estadual do Rio Doce, Minas Gerais. Dissertação de Mestrado. Universidade Federal de Viçosa, Viçosa: UFV.

Martins, F.R. 1979. O método dos quadrantes e a fitossociologia de uma floresta residual do interior do Estado de São Paulo. Tese de Doutorado. Universidade de São Paulo, São Paulo.

Martins, F.R. 1991. Estrutura de uma floresta mesófila. Campinas: Editora da UNICAMP.
Mueller-Dombois, D. \& Ellenberg, H. 1974. Aims and methods of vegetation ecology. New York: John Wiley \& Sons.

Silva, L.A. 2001. Levantamento florístico e estrutura fitossociológica do estrato arbóreo de um fragmento de floresta estacional semidecidual no município de São Carlos - SP. Tese de Doutorado. Universidade Federal de São Carlos, São Carlos.

Struffaldi-De-Vuono, Y. 1985. Fitossociologia do estrato arbóreo da floresta da Reserva do Instituto de Botânica (São Paulo, SP). Tese de Doutorado. Universidade de São Paulo, São Paulo.

Tabanez, A.J.; Viana, V.M. \& Dias, A.S. 1997. Consequiências da fragmentação e do efeito de borda sobre a estrutura, diversidade e sustentabilidade de um fragmento de floresta de planalto de Piracicaba, SP. Rev. bras. Biol. 57(1):47-60.

Tolentino, M. 1967. Estudo crítico sobre o clima da região de São Carlos. Concurso de monografias municipais. São Carlos. 78p.

Viana, V.M. 1987. Ecologia de populações florestais colonizadas e recuperação de áreas degradadas. In: Simpósio sobre Ecossistemas da Costa Sul e Sudeste Brasileira: Síntese dos conhecimentos. São Paulo: ACIESP, 1:20-39.

Viana, V. M. 1990. Biologia e manejo de fragmentos florestais. In: Anais $6^{\circ}$ Congresso Florestal Brasileiro, 1990. Campos do Jordão, p. 113-8.

Victor, M.A.M. 1975. A devastação florestal. São Paulo: Sociedade Brasileira de Silvicultura.

Walter, B.M.T. 1993. Técnicas de coleta de material botânico arbóreo. Brasília. Embrapa - Cenargen. (EMBRAPA - CENARGEN, Documentos, 15). 